\title{
Experimental investigation on heat extraction from a rock bed heat storage system for high temperature applications
}

\author{
Denis Okello *1
}

\author{
Ole J. Nydal ${ }^{2}$
}

Karidewa Nyeinga ${ }^{1}$

Eldad J. K. Banda ${ }^{1}$

1 Department of Physics, Makerere University, PO Box 7062, Kampala, Uganda

2 Department of Energy and Process Engineering, Norwegian University of Science and Technology, PO Box 7491, Trondheim, Norway

\begin{abstract}
Solar energy is available in an intermittent way, and integrating an energy storage system with solar energy collection devices may promote uninterrupted supply of energy in the absence of the availability of solar energy. It has been shown that heat can be stored using rocks packed in a bed, but limited work has been reported on heat extraction from a charged rockbed. This paper reports on the heat extraction from a charged rock bed. Discharging tests were performed under different air flow conditions and initial bed temperatures. Without the blower, the discharging rate is very slow. The discharging rate can be increased, and the cooking time controlled by adjusting the air speed through the rock-bed system.
\end{abstract}

Keywords: rock bed storage, heat extraction, air flow rates, boiling

\footnotetext{
* Corresponding author. Tel: +256 772 59403;

Email: dekello@yahoo.com

DOI: http://dx.doi.org/10.17159/2413-3051/2016/v27i2a1339
}

\section{Introduction}

Solar energy offers an alternative solution to the current energy demand from low- to high-temperature domestic and industrial applications. The conversion of solar radiation to thermal energy for direct use is particularly more attractive for both industrial and domestic heating applications. The domestic application of solar thermal systems includes solar water-heating, solar drying, solar cooking and space-heating systems. Most developing countries in sub-Saharan Africa are in dire need of energy for food preparation and yet they are located within the sunbelt region. Most communities in the rural villages rely on woodfuel for cooking. The use of solar energy to cook has several advantages, including: saving rural women and children from the burden of walking long distances in search of firewood; improving the health of these people since they will no longer be as exposed to the danger of inhaling smoke caused by incomplete biomass combustion; and reducing the current high rate of deforestation in most parts of the world. Substantial research has been reported on solar cookers [1]-[6], but these solar cookers still need improvements for them to have a wider acceptance, since their use is restricted to the sunny periods of the day. This can be remedied by integrating a thermal energy storage (TES) system for storing energy during time of availability for later applications.

The use of rock particles to store heat has several advantages compared to other thermal energy storage: they are cheap and locally available, the technology is feasible and the storage containment design is similar to the conventional cooking oven 


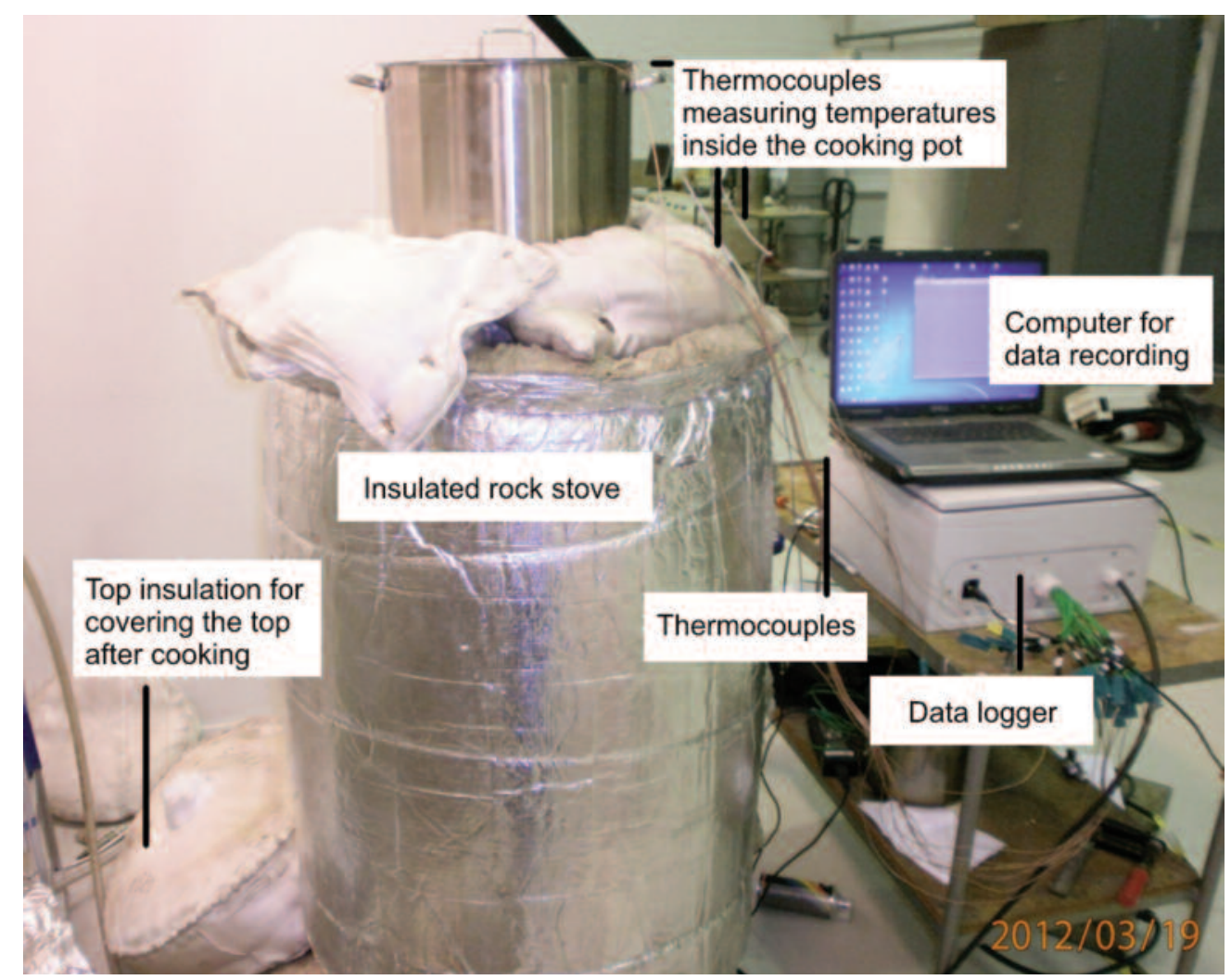

Figure 1: A rock bed stove showing the cooking pot, data logging and recording systems, top insulation for covering the top part after cooking, and thermocouples measuring the temperature inside the cooking pot and that of the rock bed storage as a function of time

which promotes cooking on the top part of the storage. In addition, rocks have fairly good heat transfer characteristics when used with air at low velocities and can withstand high temperatures [7], [8].

Studies have shown that heat in the medium-tohigh temperature range $\left(200-400^{\circ} \mathrm{C}\right)$ can be stored in a bed of rocks [9], [10]. There has, however, been limited research reported on heat extraction from a heated rock bed. This paper, investigates heat extraction from a charged bed of rocks and the thermal behaviour of the storage during this process. Since most food preparation in rural homesteads in developing countries involves boiling vegetables in water (mainly cassava, vegetables, maize grain, groundnuts, eggs, pumpkins, matooke, sweet potatoes, etc), and given that these food items do not take long to cook once the boiling point is attained [11], the study on heat extraction is limited to the time it takes to boil a given amount of water.

\section{Experimental methods}

The rock bed TES was constructed using two vertical co-axial cylinders made from stainless steel. The diameters of the inner and outer cylinders were 30 and $40 \mathrm{~cm}$ respectively. Three thin, parallel, and reflecting steel foils were inserted in the space between the cylinders to minimise heat loss by radiation. In attempt to eliminate heat loss to the surroundings, the bed was insulated with additional layers of fibreglass material, as shown in Figure 1.
The top part of the experimental TES system reported by Okello et al. was modified as shown in Figure 2 [9]. The top plate was constructed using an aluminum plate of thickness $10 \mathrm{~mm}$, and to it were attached fins made of the same aluminum material, as seen in Figure 2A. Fins were used to enhance the heat transfer from air to the top-plate. The simulated approach described by Chikukwa [12], [13] of using packed thin copper pins attached to a top plate was not considered, since the copper pins were not available. The heat extraction tests were performed by reversing the airflow direction and, from our design, it was not possible to recirculate the airflow. The direction of airflow was reversed by placing the fan at the bottom of the storage. A hole was left at the centre of the plate for letting air in and out during charging and discharging processes, as depicted in Figures 2A and B. This discharging procedure allows the thermal stratification of the storage to be retained and gives a better heat transfer to the cooking pot than by the metallic contact alone. A 20 litre saucepan containing a known amount of water was used for the boiling tests. The change in the temperature of water with time was recorded by placing a thermocouple in the middle of the water. The thermocouple tip was bent upwards to ensure that it did not touch the base of the saucepan. The variations in axial temperatures of the TES unit were also recorded.

The schematic layout of thermocouples at differ- 


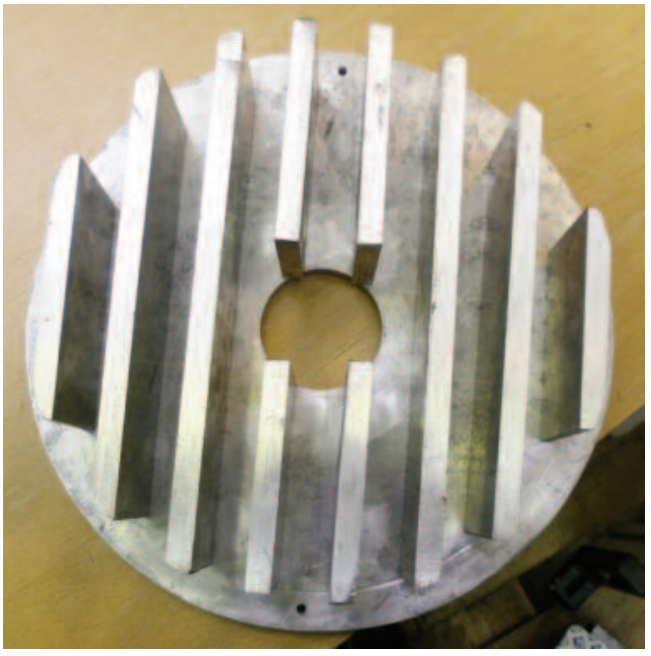

A: Top plate with fins attached

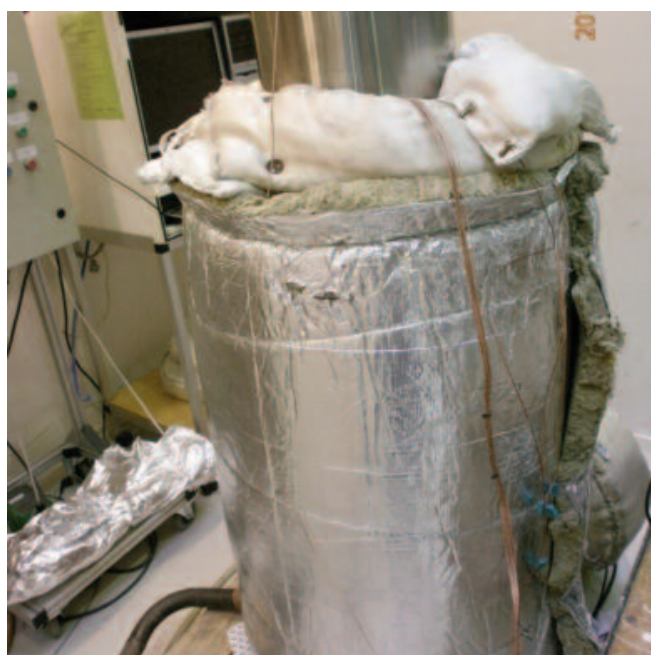

C: Water in saucepan on cooking plate

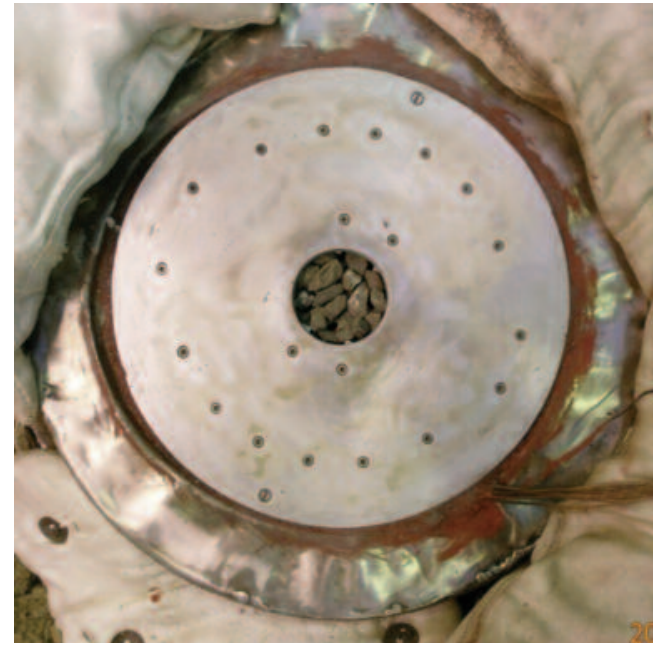

B: Top part used (cooking plate)

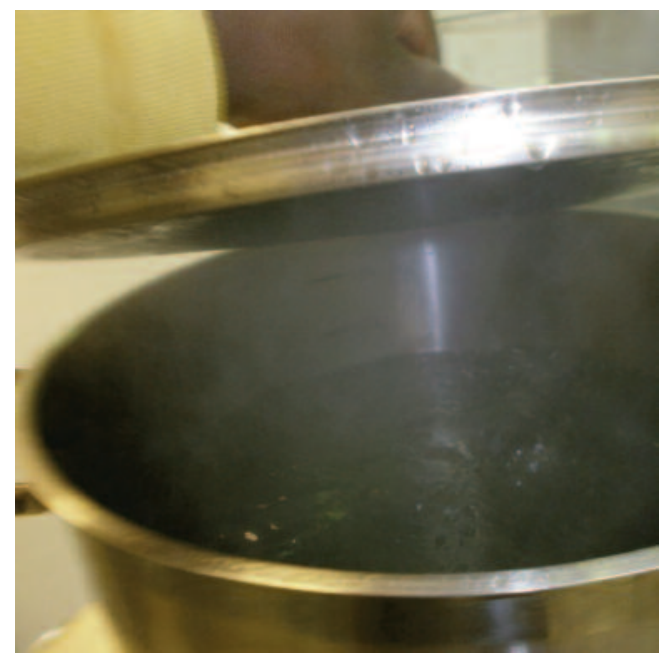

D: Water boiling on cooking plate

Figure 2: The design and construction of the top plate (A and B), and the complete rock bed storage unit during the cooking test (C); D shows a water boiling test on a rock stove

ent axial bed height is shown in Figure 3. The topmost thermocouple $\mathrm{T}_{1}$ was placed $2 \mathrm{~cm}$ below the top surface of rocks. Thermocouple $T_{2}$ was placed $0.18 \mathrm{~m}$ below $\mathrm{T}_{1}$, while the succeeding thermocouples were spaced at equal distances of $0.1 \mathrm{~m}$. The positioning of thermocouples along the bed was made possible with the help of a supporting hollow steel rod. The photograph showing a complete system with data logging systems during boiling test is shown in Figure 1. The thermocouples were connected to an NI CompactPoint DAQ (data aquisition system) that was interfaced with the computer through an RS-232 cable. A LabView program was developed to read and record temperatures every minute. The minute data was displayed on the screen, making it possible to monitor the temperature dynamics at different levels of the bed during the experiment. The uncertainty in the measured temperature is estimated at \pm 1 . The thermocouple $\mathrm{T}_{7}$ was not working and was not considered.

The discharging tests were performed under condition of no airflow and under constant and varying airflow rate conditions while monitoring the temperature profiles along the bed length. Known volumes of water were placed in turns and the times taken for each to begin boiling were recorded.

\section{Results and discussion 3.1 Constant flow rates}

The cooking test on top of a rock bed heat storage was performed by considering the time it takes to bring a known volume of water to boiling point. Figure 4 shows both the temperature of water during the boiling test and the temperature profiles along the rock-bed storage. With a constant airflow rate of $4.95 \times 10^{-3} \mathrm{~kg} / \mathrm{s}$, the variation in the temperature of water was observed and recorded. The boiling test started with 12 litres of water and this was followed by adding one litre of water each time the boiling point was reached. The points where water was added are seen as zigzags in the heating curve for water and are marked by $A_{1}$ to $A_{6}$. In total, 


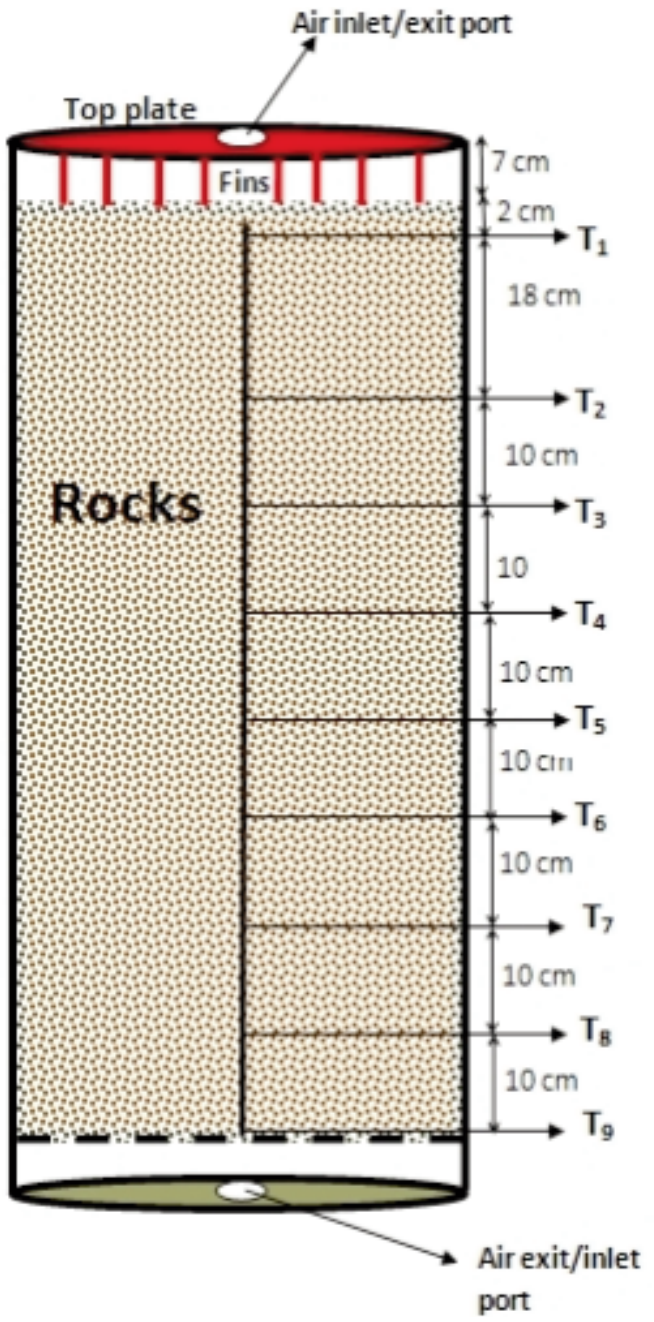

Figure 3: The schematic of the rock bed system with the top (hot) plate installed, outlining the layout of thermocouples along the bed height
18 litres of water could be boiled in about 2 hours. It took 53 minutes to bring to boiling 12 litres of water from an initial temperature of 19.2 . One litre of water was added each time the water in the saucepan began to boil. $A_{1}$ and $A_{2}$ took about 7 minutes each to begin boiling; $A_{3}$ and $A_{4}$ took 8 and 9 minutes respectively; $A_{5}$ took 12 minutes to begin boiling; while $\mathrm{A}_{6}$ took 18 minutes to reach a constant maximum temperature of 98 . At this point, most sections of the bed were at temperatures below 100 and the experiment was stopped.

The temperature distribution as a function of bed length during the cooking test is shown in Figure 5. Separations between temperature profiles after every 30 minutes are the same for a constant airflow rate discharging method.

\subsection{Varying air flow rates}

In this test, the bed was charged with a hot-air blower to almost uniform temperature at 350 and left to stabilise for about 30 minutes. The boiling times were then tested under the conditions of no airflow and varying airflow rates. In Figure 6, the boiling test was carried out by first putting three litres of water in a saucepan on the top plate of the rock bed stove but without initiating air flow. The test started with temperature at the topmost part of the bed $\left(T_{1}\right.$ ) initially at 320 which had dropped to 215 after 112 minutes. The temperature of the water in the saucepan rose from 19.8 to 85.5 in same time period. The temperature of water was observed to increase faster in the first 40 minutes from 19.8 to 77.5 , but for the next 72 minutes, a very slow rise in temperature was observed, with the thermocouples registering only 8 change. The airflow was

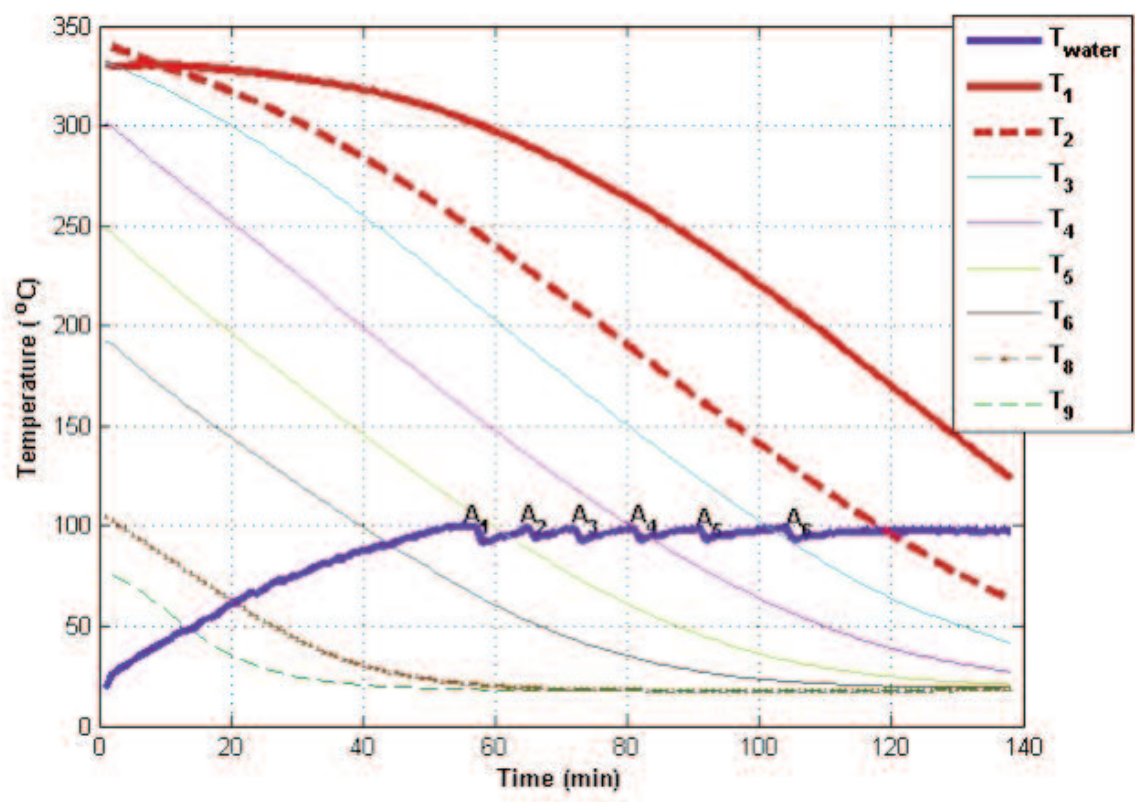

Figure 4: The temperature for water and the temperature profiles along the rock bed TES during the discharging process with a constant air flow rate of $4.95 \times 10^{-3} \mathrm{~kg} / \mathrm{s}$. $\mathrm{A}_{1-6}$ indicates points when a litre of water was added to the already boiling water in the cooking pot. 


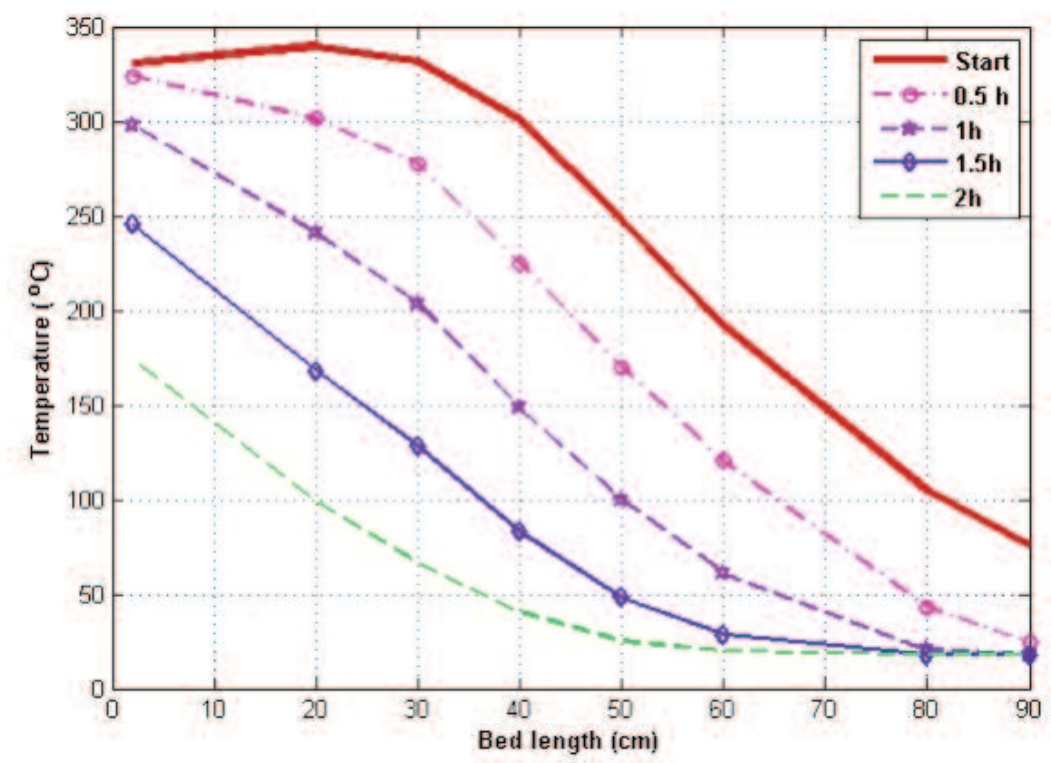

Figure 5: Temperature profiles along the bed during cooking test with a constant air flow rate of $4.95 \times 10^{-3} \mathrm{~kg} / \mathrm{s}$

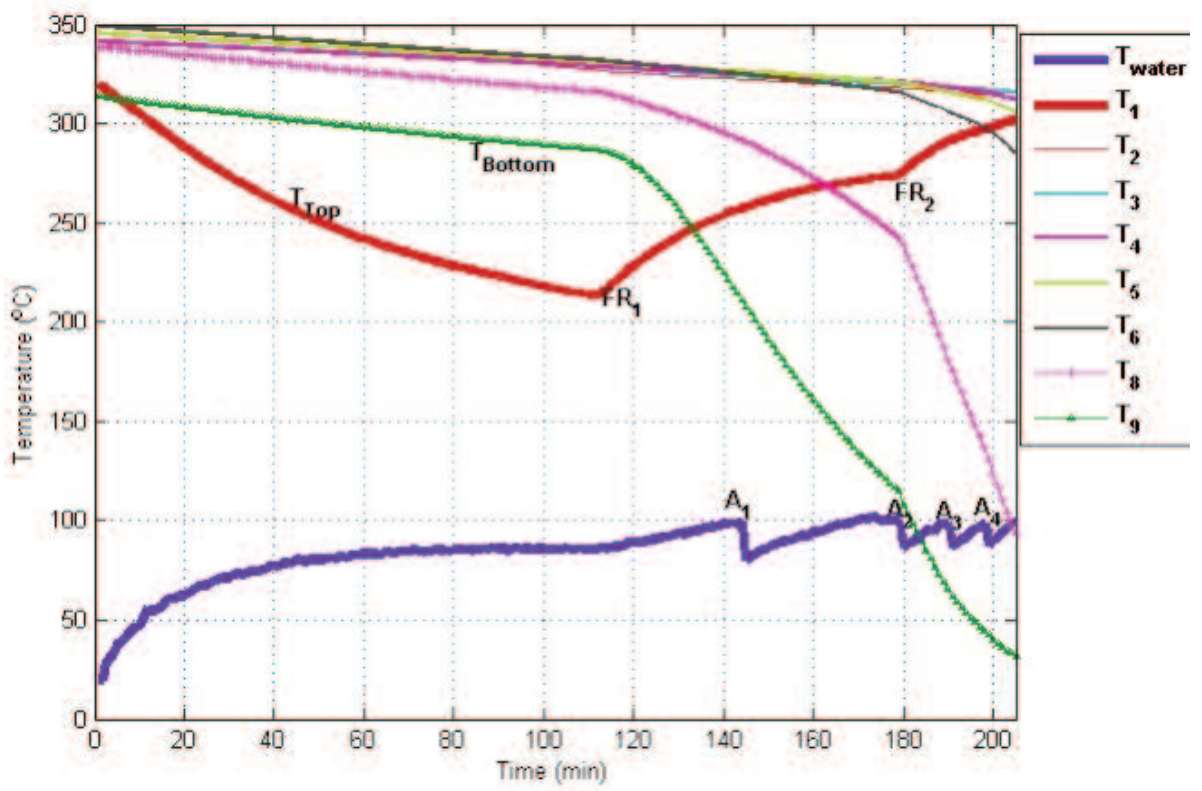

Figure 6: The heating rate of water and temperature profiles along the rock bed TES system for different airflow conditions. $\mathrm{FR}_{1}$ and $F R_{2}$ indicate points when airflow rates were changed to $2.2 \times 10^{-3} \mathrm{~kg} / \mathrm{s}$ and $3.3 \times 10^{-3} \mathrm{~kg} / \mathrm{s}$ respectively, while $A_{1-4}$ indicates points where litres of water were added.

then initiated by turning on the fan, with the airflow speed set to $2.2 \times 10^{-3} \mathrm{~kg} / \mathrm{s}$. Cold air is blown into the storage at the bottom and hot air exits through the hole at the top plate, under the cooking pot. The temperature of the water immediately started to rise and it boiled after 28 minutes. The temperature of rocks at the upper section of the bed $\left(\mathrm{T}_{1}\right)$ started to rise immediately after the fan was switched on at a point marked by $\mathrm{FR}_{1}$ in Figure 6. A litre of water at a temperature of 19.8 was then added, with the airflow speed kept constant, and it boiled in 25 minutes.

The flow speed was then increased to $3.3 \times 10^{-3}$ $\mathrm{kg} / \mathrm{s}$; it was observed to boil a litre of water in 10,7 and 6 minutes respectively. The points where units of one litre of water were added, with the flow rate changed at point $\mathrm{FR}_{2}$ to $3.3 \times 10^{-3} \mathrm{~kg} / \mathrm{s}$, are marked by $A_{2}, A_{3}$ and $A_{4}$ on the heating curve for water in Figure 6. In this case, the heating rate is observed to increase with time since the topmost part of the bed was at a lower temperature than its innermost sections.

After the boiling test was completed, the top plate was covered with the well-designed top insulation cover shown in Figure 1, and and bed was left for 13 hours. The temperature profiles showing the thermal behaviour within the bed are shown in Figure 7. The higher temperature at the top is 


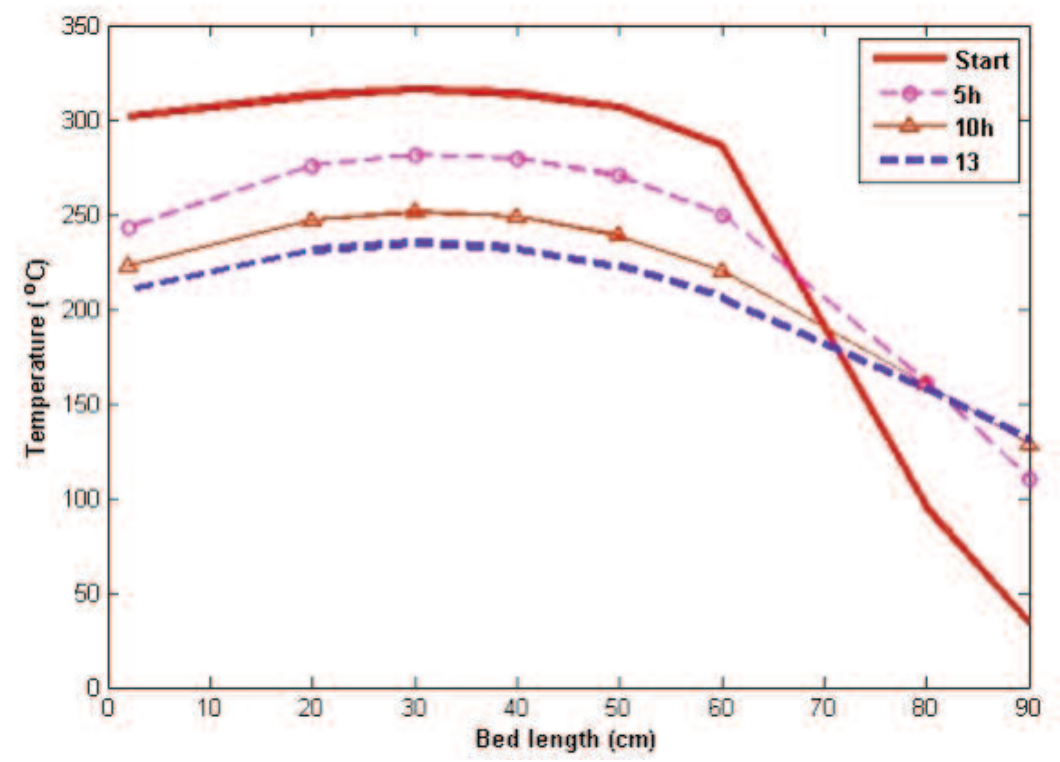

Figure 7: Thermal dynamics of an air-rockbed TES system during storage time

observed to drop as the bed approaches thermal equilibriation.

\subsection{Tests on a de-stratified rock bed TES}

The boiling test was again performed after the bed was left to equilibriate for 13 hours. Figure 8 shows the temperature profiles exhibited by both water and the rock bed TES system during discharging. The test was started by heating 7 litres of water with a constant airflow rate of $4.9 \times 10^{-3} \mathrm{~kg} / \mathrm{s}$ and it boiled in 50 minutes. The water was then changed and another 3 litres of water were again poured in the saucepan and the airflow rate was reduced to $2.9 \times 10^{-3} \mathrm{~kg} / \mathrm{s}$; it took 44 minutes for it to reach boiling temperature. This was replaced with another 3 litres of water and the air flow rate was reduced further to $0.98 \times 10^{-3} \mathrm{~kg} / \mathrm{s}$. The water was observed to heat up to constant temperature of about 86 in about 2 hours. At this point, the airflow rate was increased to $4.9 \times 10^{-3} \mathrm{~kg} / \mathrm{s}$, and boiling occurred in 10 minutes. When the pan contents were replaced by another 3 litres of water and the airflow rate increased further to $5.6 \times 10^{-3} \mathrm{~kg} / \mathrm{s}$, the water could reach only 86 . At this point all sections of the rock bed TES were at temperatures below 100 , as shown by the bed thermal profiles. These tests show that it is possible to extract heat from a charged rockbed storage by simply reversing the airflow

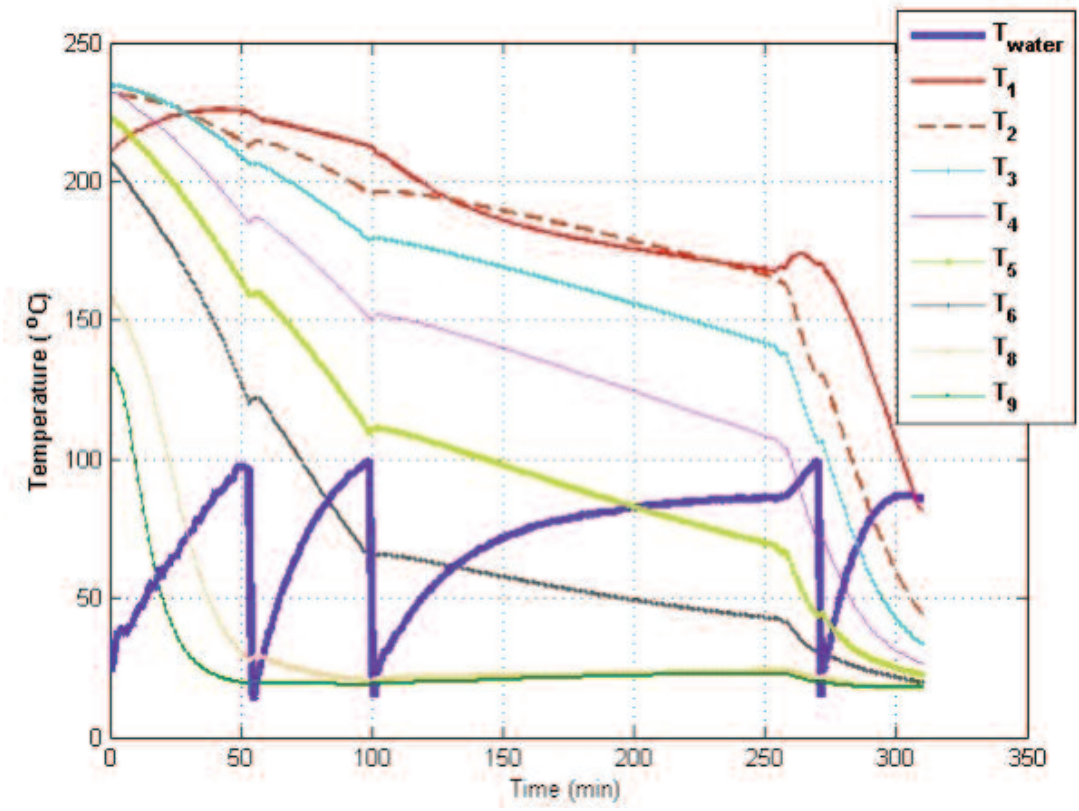

Figure 8: Heating rate of water and temperature profiles along the rock bed TES system for different airflow conditions. Zigzag points in the heating curve for water indicate points when the water was changed. The change in airflow rate is seen by changed temperature profiles along the bed. 
direction, and the extraction rates can be varied by simply adjusting the airflow speed.

The temperature profile exhibited in the rock bed TES with varying discharging air flow rates during this boiling test is shown in Figure 9. The effects of varying airflow rates on the temperature profiles of a TES unit plotted after every 30 minutes are seen from the separations between the curves. The curves are closer with slow airflow discharge rate and vice versa.

\section{Conclusions}

Discharging tests were performed by blowing air into the bottom of a heated rock bed storage under different airflow conditions. A cooking pot with water was placed on top of the heat storage, covering the opening for the hot exit air. The results for constant airflow rate discharging showed a higher rate of energy extraction in a well-stratified bed at the beginning, which then falls off with time. Without the blower, the discharging rate is very slow. The discharge rate can be increased, and the cooking time controlled by adjusting the air speed through the rock bed system. The method of discharging with varying airflow rates seems beneficial to most cooking practices since the rate can be adjusted according to the requirements of the preparation of particular foods.

\section{Acknowledgement}

The authors are grateful to the technical staff at the Department of Energy and Process Engineering at the Norwegian University of Science and Technology for the construction of the thermal energy storage system, and for the financial support to the NUFU project on smallscale concentrating solar energy systems with heat storage.

\section{References}

1. M. Telkes. 'Solar cooking ovens', Solar Energy, vol. 3, pp. 1-11, 1959.

2. B.S. Negi and I. Purohit, 'Experimental investigation of a box type solar cooker employing a nontracking concentrator'. Energy Conversion and Management, vol. 46, pp. 577-604, 2005.

3. N. M. Nahar, 'Performance and testing of an improved hot box solar cooker', Energy Convers. Mgmt, vol. 30, pp. 9-16, 1990.

4. M.A.Mohamad, H.H El-Ghetany and M.A.D Adel, 'Design, construction and field test of hot -box solar cookers for African Sahel region, Renewable Energy, vol. 14, pp. 49-54, 1998.

5. N.M. Nahar, 'Design, development and testing of a double reflector hot box solar cooker with a transparent insulation material, Renewable Energy,vol. 23, pp. 167-179, 2001.

6. A. Raji Reddy and A.V. Narasimha Roa, 'Prediction and experimental verification of performance of box type solar cooker - Part I: Cooking vessel with central cylindrical cavity', Energy Conversion and Management., vol. 48, pp. 2034-2043, 2007.

7. H.W. Fricker, 'High temperature heat storage using natural rock'. Solar Energy Materials, vol. 24, pp. 249-254, 1991.

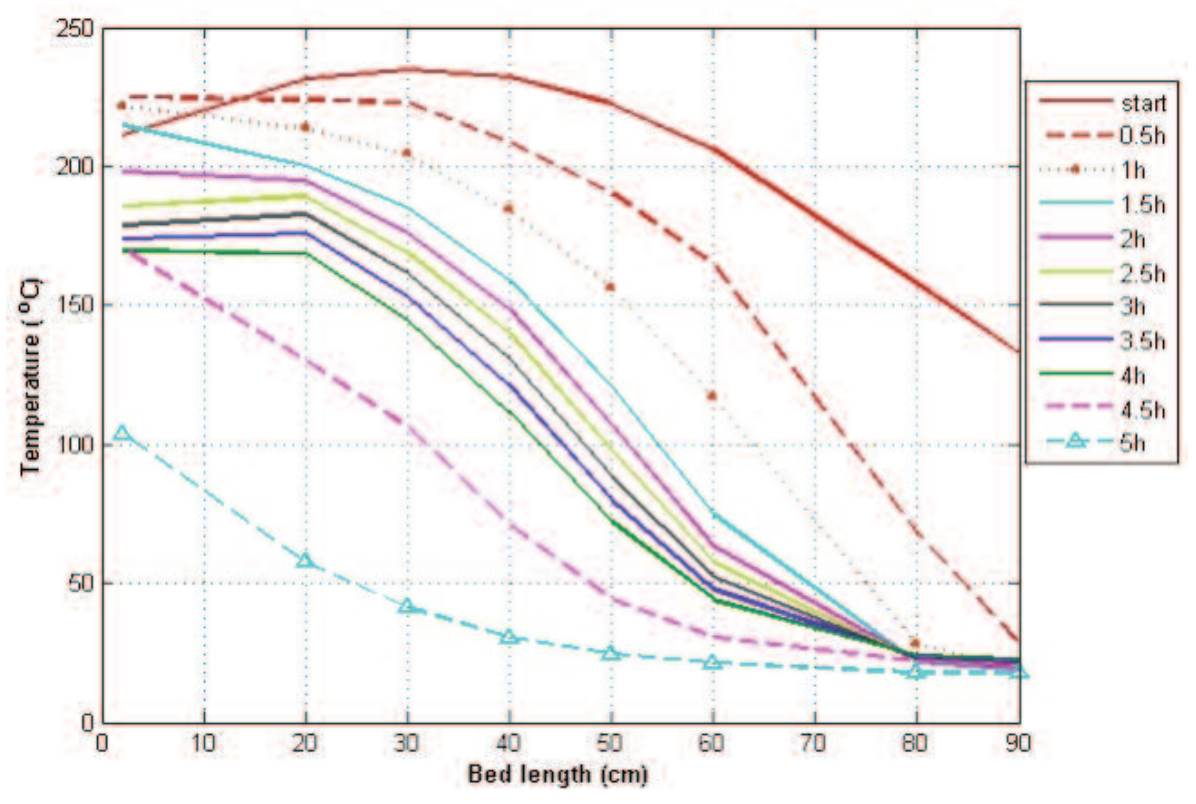

Figure 9: Rock bed temperature profiles during the third cooking test with varying flow rates test shown in Figure 8 
8. R. Daschner, S. Binder, and M. Mocker, 'Pebble bed regenerator and storage system for high temperature use', Applied Energy, vol. 109, pp.394-401, 2013.

9. D. Okello, C.W. Foong, O.J. Nydal and E.J.K.

Banda, 'An experimental investigation on the combined use of phase change material and rock particles for high temperature $\left(350^{\circ} \mathrm{C}\right)$ heat storage', Energy Conversion and Management, vol. 79, pp. 1-8, 2014.

10. D.Okello, O.J. Nydal and E.J.K. Banda,

'Experimental investigation of thermal de-stratification in rock bed TES systems for high temperature applications'. Energy Conversion and Management, vol. 86, pp.125-131, 2014.

11. B.S.M. Ali, 'Design and testing of Sudanese solar box cooker', Renewable Energy, vol. 21, pp. 573581, 2000.

12. A. Chikukwa. 'Modelling of a solar stove: Small scale concentrating system with heat storage', $\mathrm{PhD}$ thesis, Norwegian Univ. of Science and Technology, Trondheim, Norway, 2007.

13. A. Chikukwa and J. Lovseth, 'Optimization and modelling of a high temperature solar thermal storage adapted for hotplate operation', Proc. ISES Solar World Congress: Renewable energy shaping our future, pp. 660-669, 2009. 